(C) 1982. The Genetical Society of Great Britain

\title{
POLYMORPHISM FOR OUTCROSSING FREQUENCY AT THE RAY FLORET LOCUS IN SENECIO VULGARIS L. I. EVIDENCE
}

\author{
DAVID F. MARSHALL* and RICHARD J. ABBOTT \\ Department of Botany, University of St. Andrews, St. Andrews, Fife KY16 9AL, U.K. \\ Received 17.vi. 81
}

\begin{abstract}
SUMMARY
In two Edinburgh populations of Senecio vulgaris showing the ray floret polymorphism, large differences in "female" outcrossing frequency were recorded between radiate and non-radiate plants. During peaks of flowering, radiate plants exhibited "female" outcrossing rates of between 13-20 per cent while the level of "female" outcrossing shown by "non-radiate" plants never exceeded one per cent. It is postulated that the possession of pistillate ray forets by capitula of radiate plants, leading to the occurrence of functional protogyny in such capitula, greatly boosts the outcrossing frequency of radiate plants relative to that of non-radiate plants. It is suggested that the polymorphism for outcrossing frequency at the ray foret locus of $S$. vulgaris could be usefully employed as a "model situation" in studies aimed at improving our understanding of the maintenance of major gene variation for outcrossing frequency in plant populations.
\end{abstract}

\section{INTRODUCTION}

WITH infinite population size and the absence of selection, migration and mutation effects, the genotypic arrays at all polymorphic loci in a population at equilibrium, are determined by the allelic frequencies and the level of random outcrossing (see Allard et al., 1968, for a full discussion). In plants, many species reproduce through a mixture of self-pollination and outcrossing (Fryxell, 1957; Jain, 1976; Allard et al., 1977; Levin, 1978) therefore a first step towards understanding the organisation of genetic variability within their populations is an accurate estimation of natural outcrossing frequencies.

Groundsel, Senecio vulgaris L (compositae) is able to set a full complement of seed as a result of its efficient self-pollination mechanism. With relatively small, inconspicuous capitula, a low pollen-ovule ratio and high autofertility (Gibbs et al., 1975), all features that are commonly associated with an inbreeding habit, a low level of outcrossing is expected to be normal in wild populations. Trow (1912) from measurements of the level of vicinism between progeny families in an experimental garden, reported that the natural outcrossing frequency of $S$. vulgaris is in the region of ten per cent. Recently, Hull (1974), using an indirect estimation procedure, found outcrossing to average approximately one per cent in groundsel populations in Central Scotland, though some populations had levels of heterozygosity consistent with up to 15 per cent outcrossing. Measurement of outcrossing rates of a number of inbred lines raised in an experimental field plot (Campbell and Abbott, 1976) has revealed that outcrossing can average 22 per cent.

* Present address: Department of Agricultural Botany, University College of Wales, Aberystwyth, Dyfed SY23 3DD. 
The aim of the present study was to directly estimate the levels of outcrossing within two natural populations of $S$. vulgaris located in Edinburgh, Scotland. As in the previous studies mentioned above, outcrossing frequency has been measured at the ray floret locus.

\section{MAterials AND METHODS}

\section{(i) The marker locus}

At the ray floret locus, plants homozygous for the "non-radiate" allele, $T n$, produce capitula containing only tubular, hermaphrodite disc florets while homozygotes for the "radiate" allele, $T r$, bear capitula which in addition to a complement of hermaphrodite disc florets contain an outer ring of 8-13 pistillate ray florets (lacking anthers) with rays of approximately $6 \mathrm{~mm}$ in length (Trow, 1912). The alleles are co-dominant and heterozygotes, $\operatorname{Tr} T n$, are readily distinguished by their short, stubby ray florets.

\section{(ii) The populations}

Two populations occurring on wasteground sites in north Edinburgh were chosen for study. One population, referred to as the "Newhaven Road" population, occupied a site of approximately 2.5 hectares used over a number of years for the dumping of soil and rubble. The site carried a large weed flora with many areas of disturbed soil colonised by $S$. vulgaris. The second population, termed the "Harbour" population, occupied a site of approximately one hectare on a "reclaimed" section of Leith Harbour. On this site, vegetation cover was relatively sparse and $S$. vulgaris together with the related perennial $S$. squalidus, occurred as the dominant species.

The "Newhaven Road" population was surveyed between March and October 1978, the "Harbour" population between March and June 1978.

\section{(iii) Estimation of genetic parameters}

(1) Genotype and gene frequencies: Each month the number of flowering individuals in a population were counted and classified with respect to their genotypes at the ray floret locus. The frequency of the radiate allele, $T r$, was determined as follows:

$$
\operatorname{Tr}=\frac{2 a+h}{2 N}
$$

where $\operatorname{Tr}$ is the estimated frequency of the radiate allele, $a$ and $h$ are the numbers of radiate and heterozygous plants and $N$ is the total number of plants in the sample. The variance of the gene frequency, estimated in this manner, is given by Fyfe and Bailey (1951) as:

$$
\operatorname{var}(T r)=\frac{\operatorname{Tr} . \operatorname{Tn}(1+F)}{2 N}
$$

where $F$ is Wright's Fixation Index (see (2) below) and $T n$ is the frequency of the non-radiate allele which is simply obtained from $T n=1-T r$.

(2) Wright's Fixation Index: The census data obtained above may be used to obtain an estimate of Wright's Fixation Index which is a measure 
of departure from the genotypic proportions expected under panmixia. The maximum likelihood estimate of the Fixation Index is given by Fyfe and Bailey (1951) as:

$$
F=\frac{4 a \cdot b-h^{2}}{(2 a+h)(2 b+h)}
$$

with variance

$$
\operatorname{var}(F)=\frac{(1-F)\left[2 \operatorname{Tr} . T n+2(1-3 \operatorname{Tr} . T n) F-(1-4 T r . T n) F^{2}\right]}{2 N T r . T n}
$$

where $b$ is the number of "non-radiate" homozygotes. High values of $F$ are expected with inbreeding and associated low levels of heterozygosity.

(3) Outcrossing frequency: Estimates of "female" outcrossing frequency were made in March, May, July and September 1978, for the "Newhaven Road" population and in March and May 1978, for the "Harbour" population. Since the alleles at the ray floret locus are co-dominant it was possible to obtain separate estimates of "female" outcrossing level for both the "radiate", $T r T r$, and "non-radiate", $T n T n$, genotypes using the methods of Allard and Workman (1963). Two parameters are necessary for these estimates; the level of heterozygotes in the progenies of radiate and non-radiate plants and the allele frequencies among the adult flowering plants of the field population. Frequencies of heterozygotes in the progenies of radiate and non-radiate plants were estimated by testing approximately 30 seeds from each of 50 radiate and 50 non-radiate plants sampled from the field. Progenies were grown to the flowering stage in a heated glasshouse under lights and scored for their genotypes at the ray floret locus. Outcrossing frequencies were then calculated as follows.

$$
t_{(T r T r)}=\frac{H_{(T r T r)}}{T n}
$$

and

$$
t_{(T n T n)}=\frac{\left.H_{(T n T n}\right)}{T r}
$$

where $t_{\left(T_{r} T_{r}\right)}$ and $t_{\left(T_{n} T_{n}\right)}$ are the outcrossing frequencies of "radiate" and "non-radiate" plants respectively and $H_{(T r T r)}$ and $H_{\left(T_{n} T_{n}\right)}$ are the frequencies of heterozygotes in the progenies of radiate and non-radiate homozygotes. The variance of these estimates is approximately given by

$\operatorname{var}\left(t_{(T r T r)}\right) \approx\left(\frac{1}{T n}\right) \frac{H_{(T r T r)}\left(1-H_{(T r T r)}\right)}{N}+\left(\frac{H_{(T r T r)}}{T n^{2}}\right)^{2} \cdot \frac{T n(1-T n)}{N p}$

with the appropriate substitutions for the variance of non-radiate plants. $N p$ is the number of progeny scored in the estimate of heterozygote frequency.

Differences between the outcrossing levels of radiate and non-radiate plants were tested for significance using the heterogeneity $\chi^{2}$ test given in Jain (1979). 


\section{RESULTS}

The records for number of flowering plants at the Newhaven Road and Harbour sites in 1978, table 1, show peaks of flowering both in May and August. After flowering and seed set, individuals die and relatively few flowering plants occur within populations between one peak and the onset of another. As expected for a predominantly self-pollinated species heterozygote frequencies among the population of flowering plants were low throughout the survey period. The lowest levels of heterozygosity were recorded in the "early summer" (March-June) population at Newhaven Road (0.8-1.3 per cent) while in the "early summer" population at the Harbour site and the "late summer" (August-October) population at Newhaven Road heterozygosity ranged respectively between 2.3 and 2.6 per cent, and 2.2 and 3.3 per cent. An examination of Wright's Fixation Index, $F$, calculated for each sample (table 1 ) shows that the major variations in heterozygosity levels are significant.

At both sites a radical change was recorded throughout 1978 in the relative frequencies of the two homozygotes and thus the alleles at the ray floret locus, table 1. In a similar fashion at both Newhaven Road and Harbour sites the frequencies of the radiate genotype and allele rose from a low level in March to approximately 40 per cent in June. The rise in respective frequencies continued at Newhaven Road reaching 54 per cent in July, but thereafter declined to approximately 20 per cent by the end of October. The change in frequency of the radiate allele through the early summer would seem to reflect a difference between radiate and non-radiate homozygotes in time of flowering rather than changes in actual gene frequency caused, for example, by differential survivorship etc. Radiate homozygotes appeared to be later in reaching anthesis than normal plants over this period. The reason for the observed decline in frequency of the $T r$ allele at Newhaven Road through late summer and autumn is not readily apparent.

In keeping with the similar patterns observed at both Edinburgh sites for changes in flowering plant number and genotype and gene frequencies, an examination of the female outcrossing frequencies of radiate and nonradiate plants (table 2 ) reveals a close correlation in the variations of this parameter at each location. Of greatest significance is the finding that radiate plants always show a considerably higher level of female outcrossing than do non-radiate plants. Whereas non-radiate plants maintain an outcrossing frequency of less than one per cent at both locations and at all times of the year, radiate plants show respective female outcrossing frequencies of 15 and 20 per cent during May at the Newhaven Road and Harbour sites, and 13 per cent at Newhaven Road in late September. Even when pollinators are rare, owing either to their low population density, as in March, or preference for other species, as is likely in July, the outcrossing frequency of radiate plants, though correspondingly low, greatly exceeds that exhibited by non-radiate plants.

\section{Dissussion}

The most striking result to emerge from the present study is the large and significant difference recorded between radiate and non-radiate plants 
$\Xi$

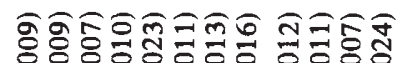

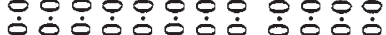

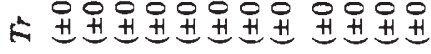

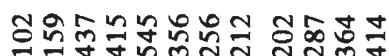

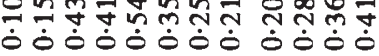

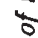

डे

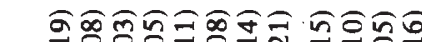
ํํㅇํํㅇํㅇํํㅇํำ

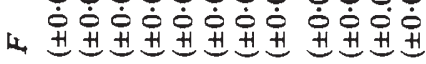

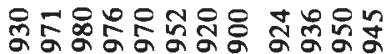

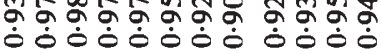

庄

ఫั

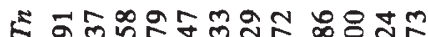

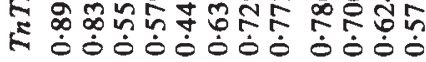

촐

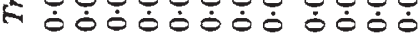

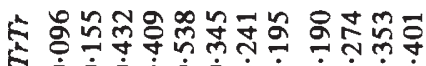

A $\dot{0} \dot{0} \dot{0} \dot{0} \dot{0} \dot{0} \dot{0} \dot{0} \dot{0} \dot{0}$

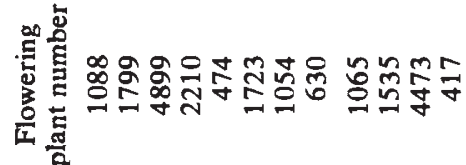

量

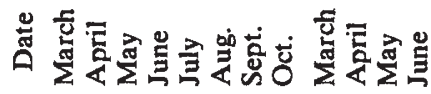

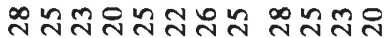
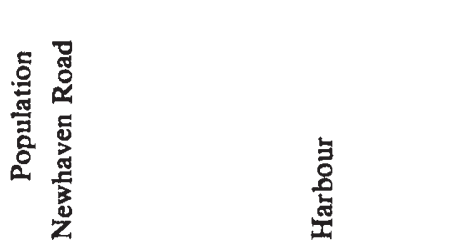
TABLE 2

Outcrossing frequencies of radiate $(\mathrm{Tr} \mathrm{Tr})$ and non-radiate ( $\mathrm{TnTn}$ ) plants in two Edinburgh populations together with heterogeneity $x^{2}$ comparisons. Standard errors of estimates are in parentheses

\begin{tabular}{|c|c|c|c|c|}
\hline Population & Sample date & $t_{(T r T r)}$ & $t_{(T n T n)}$ & $x_{(1)}^{2}$ \\
\hline \multirow[t]{2}{*}{ Newhaven Road } & $\begin{array}{l}28 \text { March } \\
23 \text { May }\end{array}$ & $\begin{array}{ll}0.028 & ( \pm 0.005) \\
0.154 & ( \pm 0.008)\end{array}$ & $\begin{array}{ll}0.007 & ( \pm 0.008) \\
0.002 & ( \pm 0.001)\end{array}$ & $\begin{array}{c}5 \cdot 3^{*} \\
327 \cdot 2^{* * *}\end{array}$ \\
\hline & $\begin{array}{l}25 \text { July } \\
26 \text { Sept. }\end{array}$ & $\begin{array}{l}0.056( \pm 0.016) \\
0.132( \pm 0.013)\end{array}$ & $\begin{array}{l}0.003( \pm 0.003) \\
0.005( \pm 0.004)\end{array}$ & $\begin{array}{l}10 \cdot 5^{* *} \\
92 \cdot 6^{* * *}\end{array}$ \\
\hline Harbour & $\begin{array}{l}28 \text { March } \\
23 \text { May }\end{array}$ & $\begin{array}{ll}0.061 & ( \pm 0.008) \\
0.199 & ( \pm 0.009)\end{array}$ & $\begin{array}{ll}0.003 & ( \pm 0.004) \\
0.007 & ( \pm 0.002)\end{array}$ & $\begin{array}{r}39.7^{* * * *} \\
390 \cdot 9^{* * *}\end{array}$ \\
\hline
\end{tabular}

of $S$. vulgaris in female outcrossing frequency (table 2). In a discussion of the possible factors that might cause this difference it is necessary to first consider whether the difference is simply an artifact of the estimation procedure employed.

A fundamental assumption of the Allard and Workman (1963) method used to estimate outcrossing frequency, is that the gene frequency in the adult population of parent plants, which is the parameter that was measured (table 1), adequately represents the gametophyte gene frequency that is effective in outcrossing. In the present study this assumption may have failed in several ways. First, in the estimation of outcrossing frequency, we have employed the parent gene frequency calculated at the time of seed sampling rather than the gene frequency at the time of fertilisation. In view of the observed change in frequency of the radiate allele through the season this is likely to have resulted in a tendency to slightly overestimate the outcrossing level of radiate plants in the early part of the year and to underestimate it in the late summer and autumn.

Second, and of greater significance, is that no account has been taken of any possible difference in the relative attractiveness of the capitula of radiate and non-radiate plants to pollinators which may have created the potential for vector-mediated gene selection at the gametophyte level. If the more conspicuous radiate plants receive a higher proportion of vector visits than would be expected from their frequency in the population, then the frequency of the radiate allele in the effective pollen pool will be higher than that in the adult population. It follows that the procedure which has been used may have led to an underestimation of the radiate allele in the effective pollen pool and thus an underestimate of the outcrossing frequency of radiate plants and an overestimate of the outcrossing of non-radiate plants in the two populations.

Finally there is the possibility that the radiate and non-radiate genotypes may differ greatly in their level of gamete production which, in turn, may result in a marked alteration in the gene frequency within the effective gamete population, as compared with that within the adult plant population. If, for example, pollen production by non-radiate plants is higher than that of radiate plants as was reported in a study by Gibbs $e$ t al. (1975), then the frequency of the non-radiate allele involved in reproduction may have been underestimated by the Allard and Workman procedure and as a result the outcrossing frequencies of radiate and non-radiate plants would have been respectively overestimated and underestimated. However, on this 
particular point, preliminary measurements of pollen number per disc floret of radiate and non-radiate plants in the Edinburgh populations (Marshall and Abbott, unpublished) indicate, that at least in these populations, the non-radiate genotype has no advantage in pollen production.

From a consideration of the various ways in which artifact may have affected the estimates of outcrossing frequency recorded in this study, it is to be concluded that though the estimates obtained may not be as accurate as desired, nevertheless the large and significant difference in outcrossing frequency between the radiate and non-radiate genotypes (table 2) is not simply a product of artifact and indeed may be of a magnitude greater than has been revealed by the procedures employed.

With the acceptance of a real difference in outcrossing frequency between radiate and non-radiate genotypes it is of interest to speculate on the probable causes. Of major importance would appear to be the direct effect that ray florets are likely to have on raising outcrossing in a selfcompatible composite. In contrast to the disc florets which are hermaphrodite, ray florets borne on the capitula of radiate plants are female and as a result of their position at the outer ring of the capitulum are the first florets to open. This means that for a time (approximately one day, depending on environmental conditions) the capitula of radiate plants, considered as functional pseudanthous units, are in fact female only. In effect the radiate capitulum is protogynous. This provides an increased opportunity for outcrossing since any pollination which occurs during this period must be either xenogamous or gneitogamous. Ornduff (1966) has previously indicated that female ray florets are likely to have a significant role in promoting outcrossing in self-compatible composites within the goldfield genus, Lasthenia and more recently Burtt (1977) has reiterated this view with respect to all self-compatible species of the Compositae that bear ray florets.

The direct affect that female ray florets are likely to have on outcrossing in $S$. vulgaris, though possibly the major reason for the higher outcrossing shown by radiate plants in the two Edinburgh populations, may be one of several factors to have contributed to the large genotype difference that has been observed. In a previous study of outcrossing in $S$. vulgaris, Campbell and Abbott (1976) found that on an experimental plot, inbred lines of the non-radiate genotype showed an average outcrossing rate of 22 per cent. This evidence demonstrates that under appropriate conditions certain non-radiate plants can achieve outcrossing levels that are much greater than were recorded in the populations at Edinburgh. Thus it is conceivable that the non-radiate genotype in the two Edinburgh populations is a peculiarly high selfing genotype which, in turn, may suggest some manifestation of local linkage disequilibrium between alleles at the ray floret locus and alleles at additional loci affecting outcrossing. Despite this possibility, it will be shown elsewhere (Marshall and Abbott, 1981) that studies of other natural polymorphic populations of $S$. vulgaris in Britain, reveal that a higher outcrossing frequency of radiate plants relative to non-radiate plants, is a consistent feature in such populations.

Finally we may turn to the evolutionary implications of the recorded difference in outcrossing frequency between radiate and non-radiate genotypes. It would seem that the difference is of major significance both for the long term fate of the ray floret polymorphism in groundsel and in 
more general terms for the fate of polymorphisms affecting outcrossing frequency in higher plants. Fisher (1941) was the first to formulate a simple single gene model of higher plant mating systems which has subsequently been developed by Moran (1962), Nagylaki (1976) and Maynard-Smith (1978) amongst others. The basic conclusion of these models is that an allele which promotes outcrossing is at a selective disadvantage when compared with an allele which promotes either selfing or lower levels of outcrossing, unless the inherent genetic cost of outcrossing is balanced by some form of selection e.g., inbreeding depression. The polymorphism for outcrossing frequency which we have found at the ray floret locus in groundsel would appear to accurately fit the basic model which these authors have developed. In addition, it would seem to have much in common with a polymorphism for gynomonoecious and hermaphrodite plants recently discussed in model form by Charlesworth and Charlesworth (1978), given, that is, that the promotion of outcrossing in radiate (gynomonoecious) plants is mainly a function of the pistillate ray florets. All of the models to date highlight the genetic cost associated with the evolution of outcrossing which suggests that it is likely to be a major factor in the long term maintenance of the ray floret polymorphism in groundsel. The polymorphism itself with its close parallels to the theoretical models would appear well suited for a future empirical analysis aimed at testing present theory and thus providing a greater appreciation of the factors that select for mixed mating systems in natural plant populations.

Acknowledgements.-D.F.M. is most grateful for the support of a Carnegie Trust Scholarship throughout the period of study.

\section{REFERENCES}

ALlARD, R. W., JAIN, S. K., AND WORKMAN, P. L. 1968. The genetics of inbreeding populations. Adv. Genet., 14, 55-131.

Allard, R. W. KAHLER. A. L., AND ClEGG. M. T. 1977. Estimation of mating cycle components of selection in plants. In Christiansen, F. B., and Fenchel, T. M. (eds.) Measuring Selection in Natural Populations, Springer-Verlag, Berlin, pp. 1-19.

ALlARD, R. W.. AND WORKMAN. P. L. 1963. Population studies in predominantly self pollinated species. IV. Seasonal fluctuations in estimated values of genetic parameters in lima bean populations. Evolution, $18,470-480$.

BURTT, B. L. 1977. Aspects of diversification in the capitulum. In Heywood, V. H., Harborne, J. B., and Turner, B. L. (eds.) The Biology and Chemistry of the Compositae, voll. I, Academic Press, London, pp. 41-59.

CAMPBELl. J. M., AND ABBOTT. R. J. 1976. Variability of outcrossing frequency in Senecio vulgaris L. Heredity, 36, 267-274.

CHARLESWORTH, D., AND CHARLESWORTH, B. 1978. Population genetics of partial malesterility and the evolution of monoecy and dioecy. Heredity, 41, 137-153.

FISHER, R. A. 1941. Average excess and average effect of a gene substitution. Ann. Eugen., 11, 53-63.

FRYXELL. P. A. 1957. Modes of reproduction in higher plants. Bot. Rev., 23, 135-233.

FYFE. J. L., AND BAILEY, N. T. J. 1951. Plant breeding studies in leguminous forage crops. I. Natural crossing in winter beans. J. Agr. Sci., 41, 371-378.

GibBS, P. E.. MILNE, C., AND VARGAS-CARRILlO. M. 1975. Correlations between the breeding system and recombination index in five species of Senecio. New Phytol., 75, 619-626. 
HULL, P. 1974. Self-fertilisation and the distribution of the radiate form of Senecio vulgaris L., in Central Scotland. Watsonia, 10, 69-75.

JAIN, S. K. 1976. The evolution of inbreeding in plants. Ann. Rev. Ecol. Syst., 7, 469-495. JAIN, S. K. 1979. Estimation of outcrossing rates: some alternative procedures. Crop Sci., 19, 23-26.

LEVIN, D. A. 1978. Some genetic consequences of being a plant. In Brussard, P. F. (ed.) Ecological Genetics: The Interface, Springer-Verlag, New York, pp. 182-212.

MARSHALL, D. F., AND ABBOTT, R. J. 1981. Polymorphism for outcrossing frequency at the ray floret locus in Senecio vulgaris. II. In preparation.

MA YNARD-SMITH, J. 1978. The Evolution of Sex. Cambridge University Press.

MORAN, P. A. P. 1962. The Statistical Processes of Evolutionary Theory. Oxford University Press.

NAGYLAKI, T. 1976. A model for the evolution of self-fertilisation and vegetable reproduction. J. Theor. Biol., 58, 55-58.

ORNDUFF, R. 1966. A biosystematic survey of the goldfield genus Lasthenia (Compositae: Helenieae). Univ. Calif. Publ. Bot., 40, 1-92.

TROW, A. H. 1912. On the inheritance of certain characters in the common groundsel, Senecio vulgaris $\mathrm{L}$., and its segregates. J. Genet., 2, 239-276. 